\title{
Chongqing High-tech Industry Performance Evaluation
}

\author{
Lihua Yang ${ }^{1, a}$ Wenbin $\mathrm{Ma}^{1, \mathrm{~b}}$ \\ ${ }^{1}$ Economics and Management School, Chongqing Normal University, Chongqing, China \\ acqtg2014@163.com, bhhtg01@163.com
}

Keywords:High-tech industry, Innovation Performance, Super Efficiency DEA Approach, Autoregressive Distributed Lag Model

\begin{abstract}
The technology innovation performance of high tech industry in Chongqing 1997-2013 is studied by using the super efficiency DEA and ARDL model. Firstly, the relative effective and invalid years of DEA are analyzed from the technology and scale of input output, and the projection value of the invalid years is improved. Secondly, the introduction of lag concept, the ARDL model to analyze the regional investment the influence degree of the factors on innovation output. Finally, this paper puts forward the pertinence suggestion of improving the technological innovation performance of high tech industry in Chongqing.
\end{abstract}

\section{Introduction}

High-tech industry is a focus of theorists. Many scholars have harvested some original, creative research findings from this field. Wang Changchun(2011) used panel data to explore the innovation performance of high-tech industries in China's 26 provinces (and municipalities) by the stochastic frontier method[1]. Liu Xin(2013) employed the factor analysis method to carry out a comprehensive evaluation, which vertically and horizontally evaluated the innovation performance of high-tech industries in multiple regions and, on this basis thereon, further analyzed factors affecting regional innovation[2]. QianWenyu(2014) used the 2009-2011 data of China's high-tech industry in technological innovation to study the efficiency of innovation, analyze the problem of excessive investment, and propose recommendations for improvement[3].

Nowadays, few scholars would apply super-efficiency DEA approach and ARDL model to analyze DEA inefficiencyyearsand study the impact of input elements on innovation output via the autoregressive distributed lag (ARDL) model. This paper studied the technological innovation of Chongqing's high-tech industry on the basis of super-efficiency DEA approach and ARDL model; employed GDP deflator to eliminate price fluctuations and principal component analysis to reduce the dimension for data processing; introducedlag and ridge regression into the model; and gave some suggestions on how to improve.

\section{DEA Empirical Analysis of Innovation Performance: Based on Chongqing Data}

Evaluation Indicator System and Data.Based on the following inputs and outputs, the innovation performance of Chongqing's high-tech industry was evaluated from the perspective of multiple inputs/outputs, that is, using the DEA approach to select multiple inputs and multiple outputs to evaluate their performance. In this study, input and output indicators were preliminarily selected in strict line with the principle of scientificity, effectiveness, and feasibility. Input indicators involved 
manpower input, financial input, and material input, and output indicators were comprised of intermediate outputs and final outputs, as shown in Table 1 below:

Table 1: Preliminary Input and Output Indicators for Performance Evaluation

\begin{tabular}{|c|c|c|c|c|c|}
\hline \multicolumn{3}{|c|}{ Input Indicators } & \multicolumn{3}{|c|}{ Output Indicators } \\
\hline Type & Name & Unit & Type & Name & Unit \\
\hline \multirow{2}{*}{$\begin{array}{c}\text { Manpower } \\
\text { Input } \\
\end{array}$} & No. of employees on average & & \multirow{3}{*}{$\begin{array}{c}\text { Intermediate } \\
\text { Outputs }\end{array}$} & No. of patent application & \\
\hline & Researchers full-time equivalent & Persons per annum & & cases & \\
\hline \multirow{2}{*}{$\begin{array}{c}\text { Financial } \\
\text { Input }\end{array}$} & Internal expenditure on $\mathrm{R} \& \mathrm{D}$ & In CNY 10,000 & & No. of effective patents & \\
\hline & $\begin{array}{c}\text { Expenditure on new product } \\
\text { development }\end{array}$ & In CNY 10,000 & \multirow{3}{*}{$\begin{array}{c}\text { Final } \\
\text { Outputs }\end{array}$} & $\begin{array}{l}\text { Revenue from main } \\
\text { operations }\end{array}$ & $\begin{array}{c}\text { In CNY } \\
100 \mathrm{~m}\end{array}$ \\
\hline \multirow{2}{*}{$\begin{array}{c}\text { Material } \\
\text { Input }\end{array}$} & No. of businesses & & & Revenue from sales of & In $\mathrm{CNY}$ \\
\hline & Investment in fixed assets & In CNY 10,000 & & new products & 10,000 \\
\hline
\end{tabular}

After the influence of price fluctuation was eliminated with deflator, the data of input and output indicators to be selected were calculated for Spearman's rank correlation coefficient therebetween with SPSS 19.0 After the application of the Spearman's rank correlation coefficient as benchmark to screen the input and output indicators to be selected, finally the researchers full-time equivalent, internal expenditure on $\mathrm{R} \& \mathrm{D}$, and investment in fixed assets were screened out as the input indicators and the number of efficient patents and the revenue from sales of main products were determined as output indicators (as shown in Table 2).

Table 2: Input and Output Indicators for Performance Evaluation

\begin{tabular}{cccc}
\hline Input Indicators & Unit & Output Indicators & Unit \\
\hline Researchers full-time equivalent & Persons per annum & Revenue from sales of & In CNY 10,000 \\
Internal expenditure on R\&D & In CNY 10,000 & new products & \\
Investment in fixed assets & In CNY 100m & No. of effective patents \\
\hline
\end{tabular}

Empirical Results \& Analysis.By applying the super-efficiency DEA model to calculate the super-efficiency scoresfrom the weighted input-output data via the Super-CCR-I model in software DEA-SOLVER Pro5, results are then obtained in Table 3. 
Table 3:1997-2013 DEA Super-efficiency ScoresRegardingTechnological Innovation

\begin{tabular}{|c|c|c|c|c|c|c|}
\hline DMU & $\begin{array}{c}\text { Overall } \\
\text { efficiency }\end{array}$ & $\begin{array}{c}\text { Pure technical } \\
\text { efficiency }\end{array}$ & $\begin{array}{c}\text { Scale } \\
\text { efficiency }\end{array}$ & $\begin{array}{c}\text { Scale changes } \\
\text { in yield }\end{array}$ & $\begin{array}{c}\text { Super } \\
\text { Efficiency }\end{array}$ & Ranking \\
\hline 1997 & 0.665 & 1.000 & 0.665 & irs & 0.665 & 15 \\
\hline 1998 & 1.000 & 1.000 & 1.000 & - & 1.419 & 4 \\
\hline 1999 & 0.514 & 0.753 & 0.683 & irs & 0.514 & 16 \\
\hline 2000 & 0.731 & 1.000 & 0.731 & irs & 0.731 & 12 \\
\hline 2001 & 1.000 & 1.000 & 1.000 & - & 1.170 & 6 \\
\hline 2002 & 1.000 & 1.000 & 1.000 & - & 1.173 & 5 \\
\hline 2003 & 0.701 & 0.983 & 0.713 & irs & 0.701 & 13 \\
\hline 2004 & 0.766 & 1.000 & 0.766 & irs & 0.766 & 10 \\
\hline 2005 & 0.819 & 0.902 & 0.908 & irs & 0.819 & 9 \\
\hline 2006 & 0.683 & 0.763 & 0.895 & irs & 0.683 & 14 \\
\hline 2007 & 0.447 & 0.661 & 0.677 & irs & 0.447 & 17 \\
\hline 2008 & 0.905 & 0.917 & 0.987 & drs & 0.905 & 8 \\
\hline 2009 & 1.000 & 1.000 & 1.000 & - & 1.820 & 1 \\
\hline 2010 & 0.757 & 0.806 & 0.939 & irs & 0.757 & 11 \\
\hline 2011 & 1.000 & 1.000 & 1.000 & - & 1.817 & 2 \\
\hline 2012 & 1.000 & 1.000 & 1.000 & - & 1.013 & 7 \\
\hline 2013 & 1.000 & 1.000 & 1.000 & - & 1.428 & 3 \\
\hline
\end{tabular}

NOTE: irs stands for increasing return to scale, drs for decreasing return to sale, and - for constant return to scale.

The projected value can directly reflect the current demand of a DMU for resource input and the maximum output that might be possibly obtained. It can, on the one hand, direct the DMU to optimize its allocation of resources and, on the other hand, point out the potential of the DMU for future development. Its main function is to facilitate decision-making and inspire the production of recommendations. It is known that among the 17 years from 1997 to 2013, 7 years accomplished DEA comprehensive efficiency and 10 years were evaluated as DEA inefficient in terms of Chongqing's technical output. For decision-making units with DEA inefficiency, CCR-I model (i.e. the input-oriented constant return to scale model) was used in software DEA-SOLVER Pro5, which tried to decrease its input value to improve its relative efficiency and find the cause behind DEA inefficiency. Specific calculation results are shown in Table 4 and Table 5.

Table 4: Improvement to Input Indicators for 10 Years Having High-tech Industry Non-DEA Efficiency

\begin{tabular}{c|c|c|c|c|c|c}
\hline \multirow{2}{*}{ DMU } & \multicolumn{2}{|c|}{ Researchers full-time equivalent } & \multicolumn{2}{c|}{ Internal R\&D expenditure } & \multicolumn{2}{c}{ Investment in fixed assets } \\
\cline { 2 - 7 } & Improved value & Projected value & Improved value & Projected value & Improved value & Projected value \\
\hline 1997 & -802 & 647 & -970.32 & 1926.68 & -0.97 & 1.93 \\
\hline 1999 & -1005 & 1014 & -3866.38 & 4092.96 & -1.61 & 1.71 \\
\hline 2000 & -371 & 1008 & -3706.41 & 4260.26 & -0.86 & 2.35 \\
\hline 2003 & -456 & 1066 & -9095.49 & 9907.44 & -2.37 & 5.55 \\
\hline 2004 & -366 & 1199 & -6033.86 & 11354.65 & -2.72 & 8.89 \\
\hline 2005 & -378 & 1716 & -4300.52 & 16831.96 & -4.37 & 19.83 \\
\hline 2006 & -785 & 1688 & -6258.84 & 13456.86 & -10.80 & 23.22 \\
\hline 2007 & -1638 & 1325 & -14760.44 & 11936.58 & -28.40 & 22.97 \\
\hline 2008 & -342 & 3272 & -2549.38 & 24353.90 & -3.60 & 34.43 \\
\hline 2010 & -972 & 3028 & -10489.13 & 32681.65 & -54.15 & 76.60 \\
\hline
\end{tabular}


Table 5: Improvement to Output Indicators for 10 Years Having High-tech Industry Non-DEA Efficiency

\begin{tabular}{c|c|c|c|c}
\hline \multirow{2}{*}{ DMU } & \multicolumn{2}{|c|}{ Revenue from sales of new products } & \multicolumn{2}{c}{ No. of effective patents } \\
\cline { 2 - 5 } & Improved value & Projected value & Improved value & Projected value \\
\hline 1997 & 0 & 50127.00 & 6 & 11 \\
\hline 1999 & 0 & 75318.52 & 5 & 10 \\
\hline 2000 & 0 & 84844.96 & 0 & 15 \\
\hline 2003 & 0 & 172540.93 & 13 & 27 \\
\hline 2004 & 0 & 233308.28 & 11 & 53 \\
\hline 2005 & 0 & 439126.65 & 96 & 134 \\
\hline 2006 & 0 & 458406.51 & 20 & 103 \\
\hline 2007 & 0 & 433459.37 & 0 & 152 \\
\hline 2008 & 0 & 734483.67 & 30 & 320 \\
\hline 2010 & 0 & 984305.40 & 0 & (1) \\
\hline
\end{tabular}

It is clear from the analysis that among the 10 years with DEA relative inefficiency, efficiencyscores of inputs into, and outputs from, Chongqing's high-tech industry were low and were more or less characterized by the problem of input redundancy or output deficiency. Take Year 2008 which had decreasing return to scale for an example. In 2008, the DEA efficiency was 0.905. Under the category of input indicators, the researchers full-time equivalent had an excess of 342 persons per annum, with the projected value at 3272 persons per annum; the internal expenditure on R\&D had an excess of CNY 25,493,800, with the projected value at CNY 243,539,000; and the investment in fixed assets had an excess of CNY 350 million, with the projected value at CNY 3,443 million. Under the category of output indicators, the revenue from sales of new products actually had an output the same with the projected value and the number of effective patents saw a gap of 30, with the projected value at 152 . This means that in order to achieve DEA efficiency, the researchers' full-time equivalent must be down by 342 persons per annum, the internal expenditure on R\&D down by CNY 25,493,800, and the investment in fixed assets down by CNY 360 million.

\section{ARDL-based Analysis of the Impact of Input Elements}

Variable Selection\& Dimensionality Reduction.In order to further the analysis of the impact of input indicators on Chongqing's high-tech industry innovation performance, preliminary indicators listed in Table 1 were used. As there were a excessive number of input and output indicators, they should be subject to dimensionality reduction before an empirical test should be conducted via the econometric model. Principal Component Analysis is an overall statistical analysis method which reduces a number of indicators into a few composite indicators for analysis. These few composite indicators can reflect most information of original indicators and be represented as linear combination thereof.

Manpower Input: The principal component score in terms of the average number of employees and the researchers full-time equivalent;Financial Input: The principal component score in terms of the internal expenditure on R\&D and the expenditure on new product development; Material Input: The principle component score in terms of the number of businesses and the investment in fixed assets. Innovation Output: The principal component score in terms of the number of patent application cases, the number of effective patents, the revenue from main operations, and the revenue from sales of new products. 
Table 6: Independent Variables and Dependent Variables in ARDL Model

\begin{tabular}{c|c|c|c}
\hline Independent variable & Symbol & dependent variable & Symbol \\
\cline { 1 - 2 } Manpower Input & $\mathrm{X}_{1}$ & & \\
\cline { 1 - 2 } Financial Input & $\mathrm{X}_{2}$ & Innovation Output & $\mathrm{Y}$ \\
\hline Material Input & $\mathrm{X}_{3}$ & & \\
\hline
\end{tabular}

General Model Selection.Following ADF stationarity test, sequences Y, X1, X2 and X3 were thereby obtained, which were stationary sequences of 2 nd order; meanwhile, there existed four co-integration relationships between original sequences, of which one co-integration equation implied the existence of positive relationship between output and input in the long run. In the selection of the optimal number of lags, AIC criterion was followed as a basis; so the optimal number of lags selected thereby was 2 . Thus, the general model of ARDL is as follows:

$$
Y_{t}=b_{0}+\sum_{i=1}^{2} b_{i} Y_{t-i}+\sum_{i=0}^{2} \beta_{1 i} X_{1(t-i)}+\sum_{i=0}^{2} \beta_{2 i} X_{2(t-i)}+\sum_{i=0}^{2} \beta_{3 i} X_{3(t-i)}+\mu_{t}
$$

Optimal Model Selection.After ARDL model with 2 lags was chosen as general model, equation(4) became to have 11 independent variables and 1 dependent variables as shown in Table 7.

Table 7: Right-side Variables of ARDL General Model with 2 Lags

\begin{tabular}{c|c|c|c}
\hline $\mathrm{X}_{1}$ & $\mathrm{X}_{2}$ & $\mathrm{X}_{3}$ & $\mathrm{Y}$ \\
\hline $\mathrm{dX}_{1}$ & $\mathrm{dX}_{2}$ & $\mathrm{dX}_{3}$ & $\mathrm{dY}$ \\
\hline $\mathrm{ddX}_{1}$ & $\mathrm{ddX}_{2}$ & $\mathrm{ddX}_{3}$ & $\mathrm{ddY}$
\end{tabular}

NOTE: $\quad \mathrm{dX}_{1}$ represents the data of $\mathrm{X}_{1}$ with 1 lag and $\mathrm{ddX}_{1}$ represents the data of reX $\mathrm{X}_{1}$ with 2 lags; This rule applies to others in a similar manner.

In the multiple regression, methods of variable selection mainly include the forward selection, backward elimination, and stepwise regression[7]. Taking into account the full impact of dependent variables on innovation output, this paper chose the backward elimination method to select variables. The advantage of backward elimination is that as long as an independent variable is eliminated, this variable won't be in the model any more. By applying SPSS19.0, the following 7 models were obtained. As per the progression criterion that the probability of F-to-remove be $>=0.100$, the output results from the software can be reorganized as follows in Table 8 .

Table 8: Backward Regression Results

\begin{tabular}{c|l|c|c|c|c}
\hline Model & \multicolumn{1}{|c|}{ Variable } & $\mathrm{R}^{2}$ & RectifiedR $^{2}$ & $\mathrm{~F}$ Value & P value \\
\hline 1 & $\mathrm{ddx} 1, \mathrm{ddx} 2, \mathrm{ddx} 3, \mathrm{dx} 1, \mathrm{dx} 2, \mathrm{dx} 3, \mathrm{dy}, \mathrm{x} 1, \mathrm{x} 2, \mathrm{x} 3$ & 0.994 & 0.980 & 69.801 & 0.000 \\
\hline 2 & $\mathrm{ddx} 2, \mathrm{ddx} 3, \mathrm{dx} 1, \mathrm{dx} 2, \mathrm{dx} 3, \mathrm{dy}, \mathrm{x} 1, \mathrm{x} 2, \mathrm{x} 3$ & 0.994 & 0.984 & 95.989 & 0.000 \\
\hline 3 & $\mathrm{ddx} 2, \mathrm{ddx} 3, \mathrm{dx} 1, \mathrm{dx} 2, \mathrm{dx} 3, \mathrm{dy}, \mathrm{x} 1, \mathrm{x} 3$ & 0.994 & 0.986 & 128.104 & 0.000 \\
\hline 4 & $\mathrm{ddx} 2, \mathrm{ddx} 3, \mathrm{dx} 1, \mathrm{dx} 3, \mathrm{dy}, \mathrm{x} 1, \mathrm{x} 3$ & 0.994 & 0.988 & 159.256 & 0.000 \\
\hline 5 & $\mathrm{ddx} 2, \mathrm{dx} 1, \mathrm{dx} 3, \mathrm{dy}, \mathrm{x} 1, \mathrm{x} 3$ & 0.994 & 0.989 & 206.391 & 0.000 \\
\hline 6 & $\mathrm{ddx} 2, \mathrm{dx} 1, \mathrm{dx} 3, \mathrm{dy}, \mathrm{x} 3$ & 0.992 & 0.988 & 235.447 & 0.000 \\
\hline 7 & $\mathrm{ddx} 2, \mathrm{dx} 1, \mathrm{dy}, \mathrm{x} 3$ & 0.991 & 0.988 & 286.595 & 0.000 \\
\hline
\end{tabular}

From 7 models listed in Table 8, it is clear that each model shows fairly good R2 and F, indicating a good fit of the model. For the selection of the optimal model, Model 7 was chosen by the backward elimination method for subsequent study based on the following considerations: the goodness of fit of Model 7 was only 0.3 percent less than Model 1 but the number of independent variables was reduced to 4 , and moreover each independent variable had a significant partial 
regression coefficient. Thus, Model 7, which is represented as follows, was chosen for subsequent study:

$$
\begin{aligned}
& \hat{Y}_{t}=0.711+0.577 Y_{t-1}+1.070 X_{1(t-1)}+1.169 X_{2(t-2)}-0.869 X_{3 t} \\
& \text { se }=\left(\begin{array}{lllll}
0.080) & (0.179) & (0.177) & (0.174)
\end{array}\right. \\
& t=(8.887) \\
& p=\left(\begin{array}{lllll}
(0.000) & (0.009) & (0.000) & (0.000) & \text { (0.001) }
\end{array}\right. \\
& R^{2}=0.991 ; \quad F=286.595, \quad P_{F}=0.000
\end{aligned}
$$

As can be seen from equation (5), both the innovation output and manpower input of the first year had a positive impact on the innovation output of the second year; the financial input of the first year had a positive impact on the innovation output of the third year; and the material input of the current year had a negative impact on the innovation output of the same year, which, however, isn't in line with the common sense, Because Model 7 is not only an autoregressive distributed lag model but also a multiple linear regression model, there is a need to test the stochastic error of the model for heteroscedasticity and sequence autocorrelation. In addition, also because the impact of material input of the current year on the innovation output of the same year was negative as observed from the regression, it can be inferred that there exists a serious problem of multi-collinearity between independent variables. So, the next step is to test if the stochastic error has any heteroscedasticity or sequence autocorrelation and then measure the severity of each variable's multicollinearity.

Regression Test.The probability corresponding to the statistics is 0.8378 . If the null hypothesis is accepted at the 5\% significance level, it can be considered that the stochastic error of Model 7 has no heteroscedasticity. The probability corresponding to the statistics is 0.0708 . If the null hypothesis is accepted at the 5\% significance level, it can be considered that the stochastic error of

\begin{tabular}{|c|c|c|c|}
\hline & \multirow{2}{*}{ Model } & \multicolumn{2}{|c|}{ Collinearity Statistics } \\
\hline & & \multirow[t]{2}{*}{ Tolerance } & \multirow[t]{2}{*}{ VIF } \\
\hline \multirow{5}{*}{7} & (Constant) & & \\
\hline & dy & 0.046 & 21.593 \\
\hline & $\mathrm{dx} 1$ & 0.046 & 21.957 \\
\hline & $\mathrm{ddx} 2$ & 0.101 & 9.942 \\
\hline & $\mathrm{x} 3$ & 0.023 & 42.956 \\
\hline
\end{tabular}
Model 7 has no sequence autocorrelation. From Table 9, it is known that the VIF of X2 (t-2) in equation (5) of Model 7 is close to 10 and the VIF of the other three variables are greater than 10. So there exists a strong multicollinearity between independent variables of Model 7.

Table 9: Measurement of Multicollinearity

Due to the presence of a strong multicollinearity, the material input generated a negative impact on innovation output in Model 7, which departs from common economic sense. The following is an improvement of the multicollinearity problem existing between independent variables of Model 7.

\section{Conclusions}

Years having technical inefficiency but attaining increasing scale were 1999, 2003, 2005, 2006, 2007, and 2010, where due to great attention to technological innovation, hard efforts were made to combine the self-dependent innovation with the existing innovations that had been brought in, absorbed and recreated to expand the industrial scale and promote the steady development of the industry. The year having both technical inefficiency and decreasing scale was 2008, a year 
coinciding with the eruption of the global financial crisis, and inevitably the innovation performance of Chongqing's high-tech industry was adversely impacted.

Acknowledgments: The authors are grateful for the support of the National Social Science Fund (11XSH019 and 14AJL015)

\section{References}

[1] WANG Changchun.The Research of High-tech Industrial R\&D Performance and Influencing Factors in Chinese Provinces and Regions.Hunan University.2011

[2] LIU Qin.Research on Innovation Performance of High-tech Industry and the Influential Environment Factors.Chongqing University.2013.

[3] QIAN Wenyu, CHEN Xinguo.Technical Innovation Performance Evaluation of High-tech Industry in China Based on DEA Method. Science and Technology Management Research,8(2014)196-201. 